\title{
CANT EXCESS AND CANT DEFICIENCY EVALUATION IN RELATION TO TRAIN SPEED
}

\author{
Jan Valehrach*, Tomáš Řítha, ERIK Dušek \\ Brno University of Technology, Faculty of Civil Engineering, Institute of Railway Structures and Constructions, \\ Veveři 331/95, 60200 Brno, Czech Republic \\ * corresponding author: valehrach.j@fce.vutbr.cz
}

\begin{abstract}
The paper deals with the evaluation of measured speeds of the vehicles on the chosen sections of the railway network in the Czech Republic. In connection with the phased implementation of the AVV system (automatic train operation) and the European ETCS system, the dispersion of the train speeds will be reduced. Measured data were used to assess the weighted average of the cant excess or cant deficiency in relation to the rail defects. Within the framework of the research, the speeds were statistically evaluated covering more aspects like types and sorts of the trains, their operators, daytime and more.
\end{abstract}

KEYWORDS: speed/velocity, track, train, cant excess, cant deficiency.

\section{INTRODUCTION}

In the present time speeds of trains passing through the certain place vary. The variability of the speeds depends on more factors, such as train composition and category, actual traffic situation, daytime and the location. In connection with the implementation of new systems for train controlling and commanding the speed profile of the trains will likely become more efficient. By author's opinion, this will eventually lead to the consolidation of speeds into a narrow range, or eventually into more ranges based on above mentioned factors.

The knowledge of the speeds is necessary for a number of fields in railway industry. Some of the applications, where the knowledge of speed is critical, are the studies [1]. This article focuses on the influence of speed on development of defects on superstructure by studying speed ranges in certain places of the railway infrastructure.

As a starting point for the study an expected relation between the appearance of the long-pitch corrugation in curves of small radii and the speed range of the passing vehicles was considered. Authors believe that the speed range in certain places of the infrastructure can affect the functionality of the superstructure and under specific circumstances the inappropriate speed range could result in the development of the defects of the rails. By minimizing inconvenient combinations of track parameters and the speed ranges the positive effect will likely appear, which in some extents gives us the potentiality for the optimization.

One of the possible parameters, influencing the appearance of the long pitch corrugation in curves of small radii is considered to be cant excess or cant deficiency. In standard conditions, where negative effects on infrastructure do not take place, both values are designed with the design of the track itself. In such case, the designer uses some initial expectations of future traffic composition to calculate cant values. Then uses (still only as an expectation) the track speed and calculates the values of cant excess or cant deficiency. Nevertheless, this method could not take in account the real speeds of vehicles, which may be far different from the expectations. This lack of feedback could result in some negative effects on infrastructure, and one of them is believed to be the long pitch corrugation defect.

This work focuses on evaluation of the cant excess or cant deficiency values obtained through the speed measurements while the relation to long pitch corrugation is studied.

\section{Methods of MeAsurement AND EVALUATION}

\subsection{LOCATION SELECTION}

The appearance of the long pitch corrugation was the basis for the selection of the locations for measurements. Extensive measurements took place in first track of the line from Brno to Česká Třebová between stations Adamov and Brno-Maloměřice. Four locations were selected as follows:

- Line No. 326 (Brno - Česká Třebová) near Babice nad Svitavou, km 169.0, in approximately 200 metres the first turnout of the marshalling yard BrnoMaloměřice follows;

- Line No. 326 (Brno - Česká Třebová) near Babice nad Svitavou, km 167.0, the position of the automatic block signal;

- Line No. 326 (Brno - Česká Třebová) near former branching station Hady, km 161.7;

- Line No. 326 (Brno - Česká Třebová) near former branching station Hady, km 162.8, currently the Babice stop. 


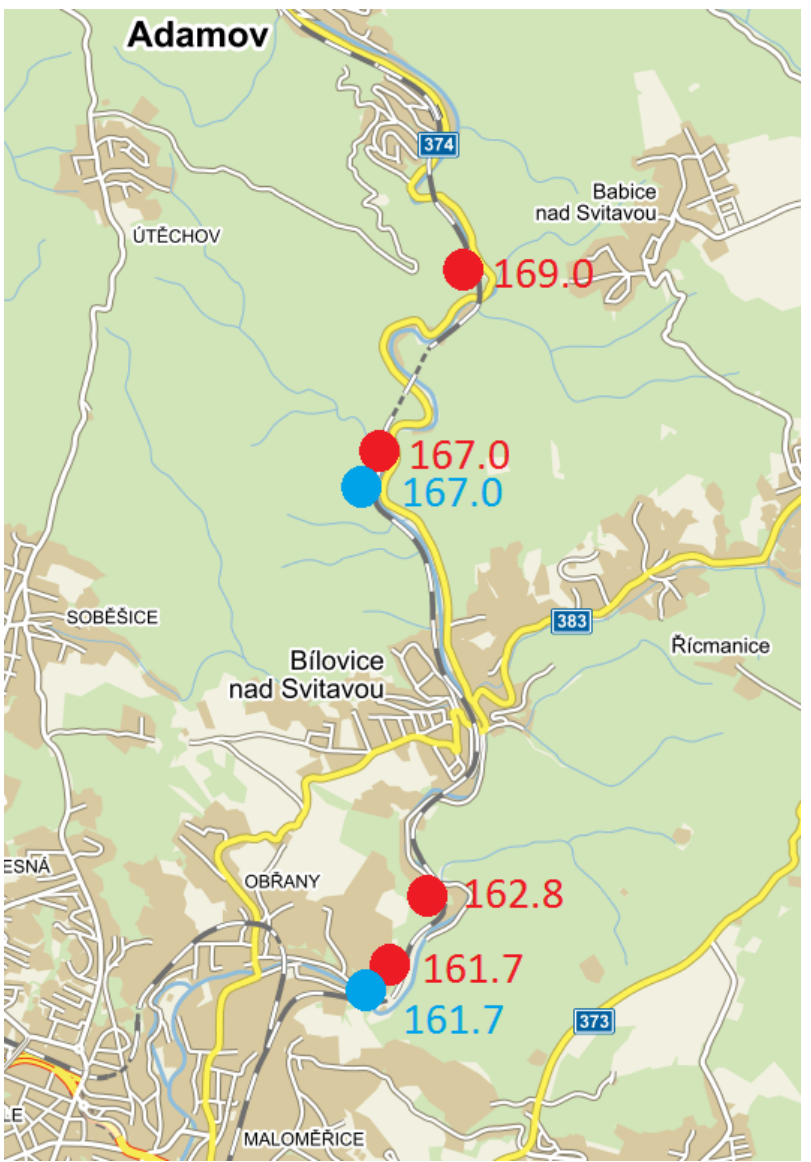

FIgURE 1. The locations positioning of speed recording device (red points) and automatic image recorder (blue points).

In all four locations the significant long pitch corrugation defect occurs.

\subsection{Measurement method}

All the measurements were continual and lasted several days. Measurements were conducted in pairs, since there are two recording devices at disposal. The pair includes the measurements in $\mathrm{km} 169.0$ and in $\mathrm{km} \mathrm{167.0,} \mathrm{the} \mathrm{second} \mathrm{pair} \mathrm{consists} \mathrm{of} \mathrm{measurements} \mathrm{in}$ $\mathrm{km} 161.7$ and in $\mathrm{km} \mathrm{162.8.} \mathrm{By} \mathrm{pairing} \mathrm{it} \mathrm{is} \mathrm{possible} \mathrm{to}$ get the speed of one particular train in two locations.

Following data were recorded for each passing train:

- Speed;

- Image record;

- Date and time of the recorded event.

As a measuring instrument for recording speeds and directions of the trains were used DRS devices (frequency modulation radar units). The main advantage of the device is the possibility of the quick on site installation and measuring without any external energy supply due to device batteries. On the other hand, the device tends to record more than one speed of the train, partially due to the response time and partially due to the length of the trains, which exceeds the length of the vehicles for which was the device initially built 11 Thus, longer trains inflict more measurements and more records. Such sets of records then have to be sorted out by hand, which is very challenging work. The aim is to choose only the speed record which corresponds with the speed of a head of a train. Mostly, the first record is chosen, but in some cases careful consideration has to take place.

\subsection{Evaluation}

Following information about the particular train is then searched out based on the image record, train traffic diagram, timetable, train compositions list and others:

- Category (freight train, express, passenger train and more - see below);

- Train number;

- Composition of the train or train set, types of couches;

- Train mass;

- Delay.

Despite of a great amount of endeavour some trains could not be identified satisfactory. Also some measurements had to be edited out, mainly the ones anticipated faulty. At the end, in every of all four locations at least 200 trains were evaluated.

\subsection{Calculation method}

A weighted average of all speed measurements in a location was calculated, when the mass of each train was taken into consideration [4].

The masses of the trains for the purposes of the weighted averages have been obtained by two ways. The weight of passenger trains was taken from the passenger carriages charts and from the train compositions list. The mass of the freight trains could be found out from the mass normative (which is the maximum allowable mass of the whole train). The problem is that the actual load on the train is not known and thus it is not possible to know the right mass of the train. Therefore, the masses of the freight trains were estimated with the value 1000 tonnes? 2 . This approach brings the significant amount of uncertainty to the result, but on the other hand, according to higher order masses of the freight trains in comparison to the passenger trains, the sensitivity of the result to the changes of the masses is quite small.

Then for the calculation of the cant excess and the cant deficiency the following scheme was used [5]. Values of radii and cant for every location were taken from Superstructure plotted outline [6].

\footnotetext{
${ }^{1}$ Used devices were initially designed for recording of road vehicles not exceeding the length of 18 metres.

${ }^{2}$ Despite of a fact that this simplification seems to be very disproportional, the results later imply, that the influence of a train masses on the cant excess and cant deficiency is not as strong as was expected. In the present time authors believe, that the influence of the train mass could be negligible. By all means, this still certainly has to be researched more thoroughly.
} 
Assuming a formula for ideal speed of trains

$$
V=\sqrt{\frac{D \times R}{11,8}}
$$

The cant excess of a single train then applies

$$
E_{i}=D-\frac{11,8 \times V_{i}^{2}}{R}
$$

and analogically for the cant deficiency

$$
I_{i}=\frac{11,8 \times V_{i}^{2}}{R}-D
$$

Ideally, the effects of cant excess and deficiency should be balanced, especially with respect to train masses. However, in general in some locations cant excess could markedly dominate. That happens for example in the vicinity of stations, where the trains are accelerating and have not yet reached the track speed or where the greatest amount of the track load consists of slow moving trains (usually freight trains). In such locations this leads to the overload of the railway superstructure and consequently results in increased occurrence probability of the defects.

\section{Outputs}

\subsection{SPEED RANGES}

The first look at the cleaned data inserted into the charts is promising. The charts below show all four evaluated locations. The speed ranges are apparent, and also the variability could be easily distinguished. The width of the ranges could be identified as well.

The width of the speed range has to be considered separately from the variability. The variability describes more the whole dispersion of the measured values, whileas the speed range could be in most cases identified not only once (namely in first chart there could be identified the upper speed range between 65 and 80 and the down speed range between 45 and 60). The speed range however should include the category of trains, as described below in Figure 3 and thus it is more complicated to identify it soundly.

Some of the records are separated from the speed ranges. These records are considered as anomalies; since they are isolated, the passes of the trains corresponding to these records cannot have any significant influence on the infrastructure ${ }^{3}$ For these purposes, these records are in further analysis neglected.

The following table differentiates the speeds by category of the train, showing the average values.

\subsection{CANT EXCESS AND DEFICIENCY VALUES}

For every single train the cant excess or cant deficiency was calculated. In the following charts also the categories of the trains were distinguished, showing clearly the anomalies in the traffic.

\footnotetext{
${ }^{3}$ In general, exemptions to this statement could be found, such as special transports of overweighed cargo or other similar uncommon traffic.
}

As it could be seen in the Figure 3, the highest cant deficiency values (as high as $130 \mathrm{~mm}$ ) are used by passing trains in location 162.8. However, this happens to be the location with the least cant of all monitored locations.

On the contrary, the least cant deficiency values are used by passing trains in location 169.0. In this case the track alignment consists of compound curve of a radius $375 \mathrm{~m}$ with cant $140 \mathrm{~mm}$ in first part and radius 382 and cant $100 \mathrm{~mm}$ in second part of the curve. By the end of the curve could be found the train stop. Measuring section was located in first part of this curve.

As a result of evaluation according to chapter 2.4 just one value of the weighted cant deficiency was calculated. In case of our locations, cant excess did not take place.

This value could be used for specifying the influence of all the trains passing through certain location on the infrastructure 4 .

In case of a need of a closer in-depth analysis, it is necessary to divided the trains into more groups or categories and to calculate the weighted averages afterwards.

\subsection{SELECTED CATEGORIES}

The categories were selected based on the categories of the passenger trains (also private companies were taken into account). In the future it could be expected, that the speeds will consolidate within these categories rather than by the construction and design properties of the trains.

For every category the weighted cant excess (Formula 4 ) or cant deficiency (Formula 5 ) were calculated by

$$
\begin{gathered}
E=\frac{\sum_{i}^{n} m_{i} \times E_{i}}{\sum_{i}^{n} m_{i}} \\
I=\frac{\sum_{i}^{n} m_{i} \times I_{i}}{\sum_{i}^{n} m_{i}}
\end{gathered}
$$

Results calculated using Formulas 4 and 5 are displayed in Table 2

When comparing the weighted cant excess or cant deficiency for train categories with the weighted value for all the trains according to Table 3 it could be stated, that at least for the rough estimate for the purposes of setting curves against each other is this value conclusive enough.

\subsection{TRAin SPEED/VELOCITY AND LONG-PITCH CORRUGATION}

In a framework of the research also the rate of long pitch corrugation development was monitored in locations 161.7 and 162.8. The corrugation tends to develop quicker in the curve with 162.8 , which is the curve where higher values of cant deficiency were found [7. 


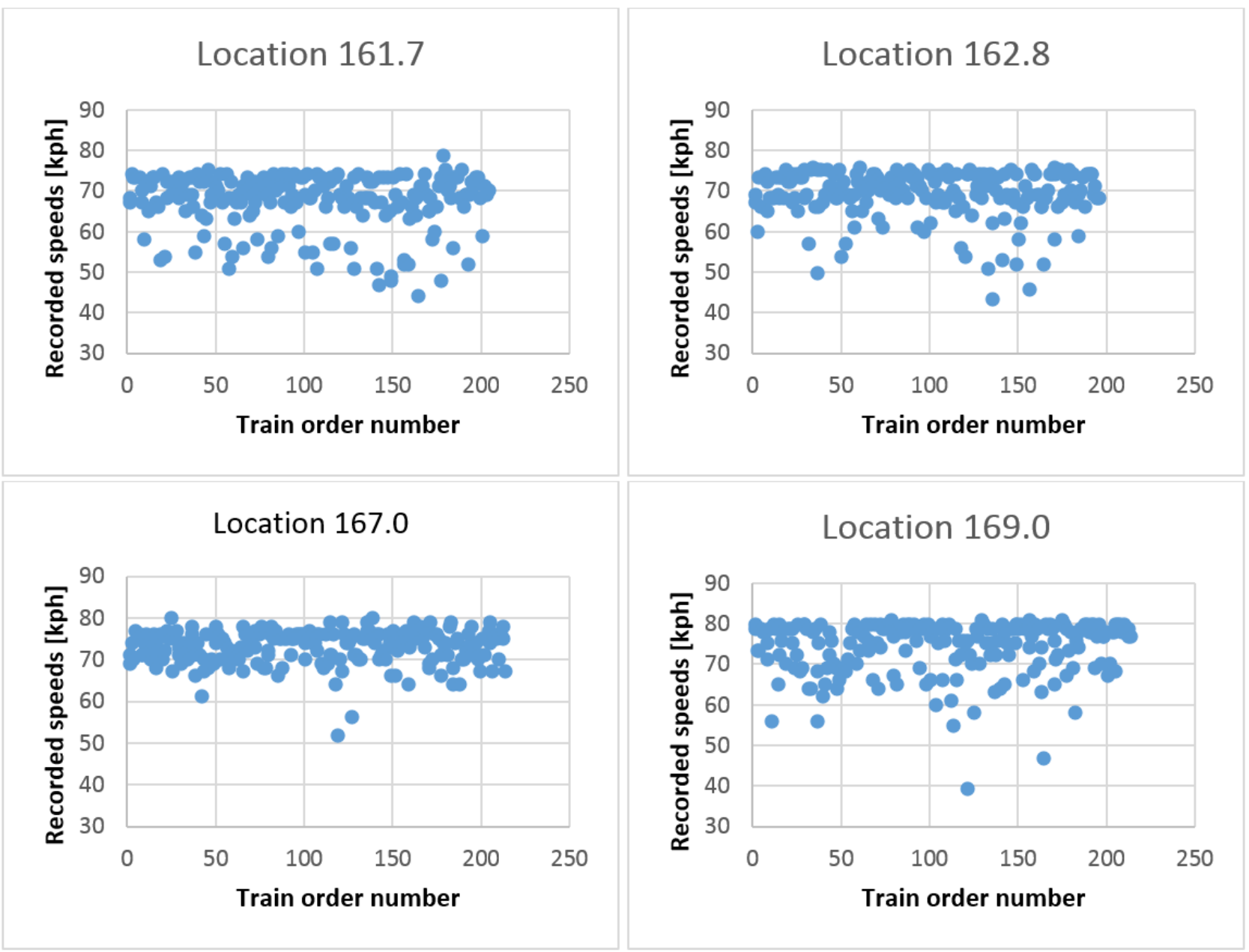

Figure 2. First look at cleaned data from all locations.

Based on this finding and also using experience from the preceding investigation it is to expect that in case of curves with locations 167.0 and 169.0 the long pitch corrugation will be developing faster in curve with 167.0.

\section{Conclusions}

The research was aimed to confirm or disprove the possibility, that cant excess or cant deficiency could influence the development of certain defects of the railway superstructure. In order to be able to calculate the actual values of cant excess or cant deficiency it was necessary to measure speed of passing vehicles. Four locations were chosen, both for comparison and for variability monitoring.

The speeds were measured with the recording devices and the trains were divided into categories of the similar speed range. After that, the calculation of the cant deficiency or cant excess was executed with double results. First set of results uses as a basis all the speed measurements across all the train categories. Second set of results respects the averages in categories detached. The results show, that even the simpler first method could bring satisfactory results.
Further research should focus on the long-term monitoring of train speeds in order to be able to calculate cant deficiency or cant excess more precise. Also more emphasis should be put into the differentiation of masses of the trains.

\section{ACKNOWLEDGEMENTS}

Research reported in this paper was supported by Competence Centres program of Technology Agency of the Czech Republic (TA CR), project Centre for Effective and Sustainable Transport Infrastructure (no. TE01020168), Student's grant tender of the Faculty of the Civil Engineering of the Brno University of Technology (FAST-J-15-2860) and Railway Infrastructure Administration, state organization (SŽDC s. o.).

\section{REFERENCES}

[1] C. Esveld. C. Modern railway track. 2nd ed. Zaltbommel: MRT-Productions, 2001. ISBN 90-800-3243-3.

[2] J. Smutny, I. Vukusic, V. Tomandl, et al. Analýza dynamických účinků v srdcovkové části výhybek, Stavební obzor. STAVEBNÍ OBZOR, Thákurova 7, 16629 Praha 6, 2013. ISSN 1210-4027.

[3] P. Guziur. Design parameters of buffer stops. Acta Polytechnica CTU Proceedings. 2016. ISSN: 2336-5382. 


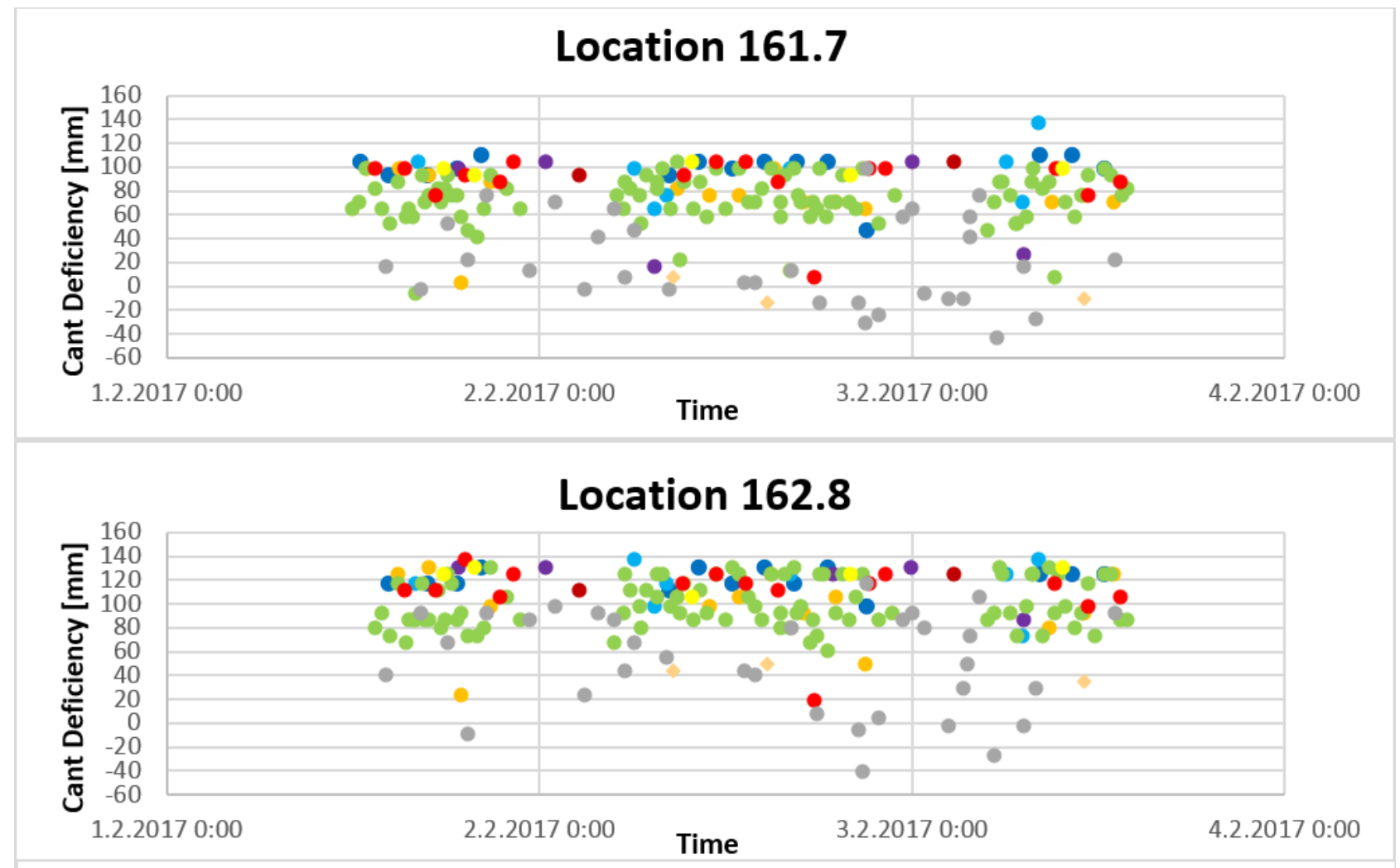

Location 167.0

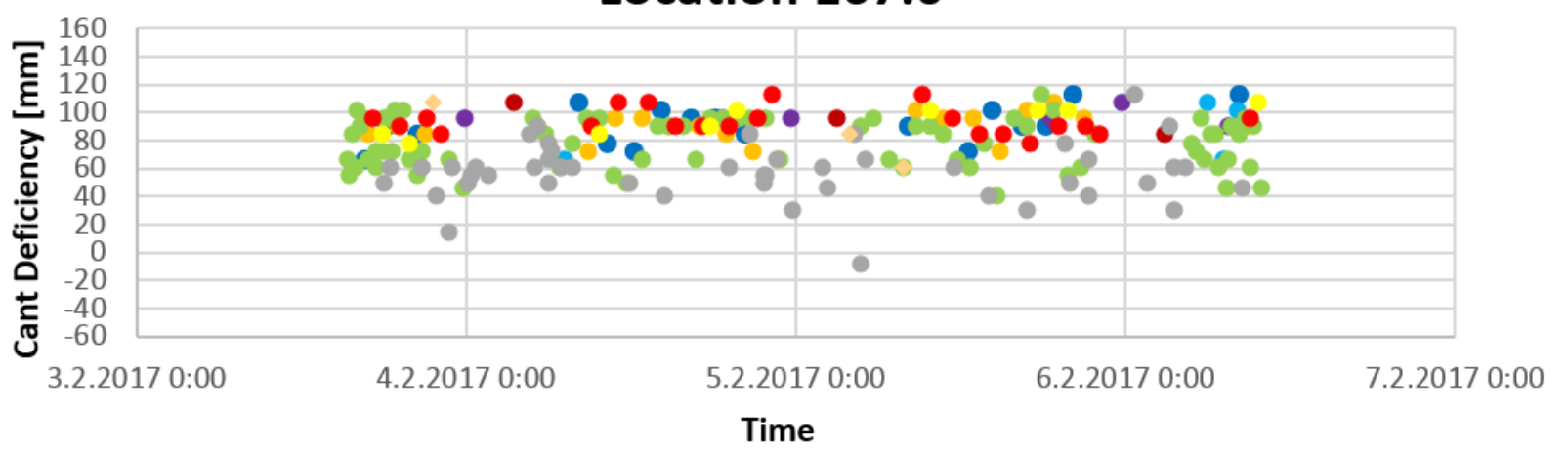

\section{Location 169.0}

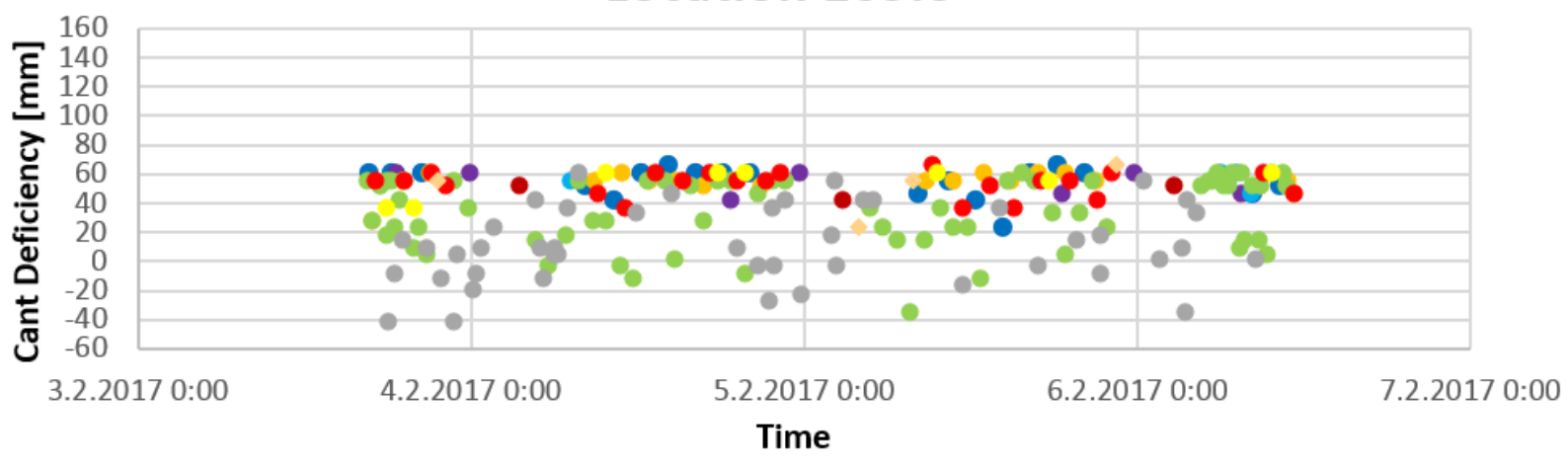

- EC • Ex • En R $\bullet \mathrm{Sp} \bullet$ Os • Railjet Regiojet Freight train Others trains

Figure 3. The comparison of the cant excess and cant deficiency in locations (Cant Deficiency [+] / Cant Excess [-]). 


\begin{tabular}{|c|l|l|l|l|l|l|l|l|l|l|}
\hline \multirow{2}{*}{$\mathrm{km}$} & \multicolumn{9}{|c|}{ Average speed V [kph] for the train category } \\
\cline { 2 - 11 } & $\begin{array}{l}\text { EuroCity } \\
\text { train }^{1}\end{array}$ & $\begin{array}{l}\text { Express } \\
\text { train }^{2}\end{array}$ & $\begin{array}{l}\text { EuroNight } \\
\text { train }^{3}\end{array}$ & $\begin{array}{l}\text { Fast } \\
\text { train4 }\end{array}$ & $\begin{array}{l}\text { Fast } \\
\text { train } \\
\text { suspended }\end{array}$ & $\begin{array}{l}\text { Passenger } \\
\text { train6 }\end{array}$ & $\begin{array}{l}\text { Railjet } \\
\text { train }^{7}\end{array}$ & $\begin{array}{l}\text { RegioJet } \\
\text { train }^{8}\end{array}$ & $\begin{array}{l}\text { Freight } \\
\text { train }\end{array}$ & $\begin{array}{l}\text { Other } \\
\text { trains }\end{array}$ \\
\hline 161.7 & 72.93 & 67.80 & 73.00 & 68.87 & 72.13 & 68.47 & 71.13 & 72.80 & 58.27 & 53.00 \\
\hline 162.8 & 73.50 & 73.40 & 73.00 & 69.57 & 72.75 & 70.09 & 71.60 & 73.80 & 61.64 & 60.67 \\
\hline 167.0 & 75.18 & 75.18 & 75.18 & 75.18 & 75.18 & 75.18 & 75.18 & 75.18 & 75.18 & 75.18 \\
\hline 169.0 & 78.68 & 78.68 & 78.68 & 78.68 & 78.68 & 78.68 & 78.68 & 78.68 & 78.68 & 78.68 \\
\hline
\end{tabular}

1 The highest category of passenger trains, calling only at major stations not less than $60 \mathrm{~km}$ away from each other, usually consisting of the locomotive and six to eleven coaches (hereinafter EC).

2 The category of passenger trains, calling only at major stations not less than $60 \mathrm{~km}$ away from each other, usually consisting of the locomotive and three to six coaches (hereinafter Ex).

3 The highest category of passenger trains running during nigh time, calling only at major stations not less than $60 \mathrm{~km}$ away from each other, usually consisting of the locomotive and more than ten coaches (hereinafter En).

4 The category of passenger trains below express trains, calling at major stations and junctions, usually represented by the train set InterPanter (hereinafter $\mathrm{R}$ ).

5 The category of passenger trains not calling at all stops, usually consisting of the locomotive and three to six coaches (hereinafter $\mathrm{Sp}$ ).

6 The usual passenger train calling at all stops. The train composition differs, both locomotive with coaches and train sets are used to cover this category (hereinafter Os).

7 The same category of passenger trains as the EuroCIty trains, consisting exclusively of the locomotive and train set Siemens Viaggio Comfort (hereinafter Railjet).

8 The same category of passenger trains as the EuroCIty trains, consisting exclusively of the locomotive and six to eleven coaches (hereinafter Regiojet).

${ }^{9}$ Covers all other categories of trains, or trains which do not have specific category, for example maintenance machines etc.

TABLE 1. Average speeds of the displayed train categories.

\begin{tabular}{|c|l|l|l|l|l|l|l|l|l|l|}
\hline \multirow{2}{*}{$\mathrm{km}$} & \multicolumn{6}{|c|}{ Weighted Cant Deficiency [+] / Cant Excess [-] in millimetres for the categories of trains } \\
\cline { 2 - 12 } & $\begin{array}{l}\text { EuroCity } \\
\text { train }\end{array}$ & $\begin{array}{l}\text { Express } \\
\text { train }\end{array}$ & $\begin{array}{l}\text { EuroNight } \\
\text { train }\end{array}$ & $\begin{array}{l}\text { Fast } \\
\text { train }\end{array}$ & $\begin{array}{l}\text { Fast } \\
\text { train } \\
\text { sus- } \\
\text { pended }\end{array}$ & $\begin{array}{l}\text { Passenger } \\
\text { train }\end{array}$ & $\begin{array}{l}\text { Railjet } \\
\text { train }\end{array}$ & $\begin{array}{l}\text { RegioJet } \\
\text { train }\end{array}$ & $\begin{array}{l}\text { Freight } \\
\text { train }\end{array}$ & $\begin{array}{l}\text { Other } \\
\text { trains }\end{array}$ \\
\hline 161.7 & 100 & 82 & 100 & 72 & 92 & 74 & 89 & 99 & 21 & -4 \\
\hline 162.8 & 122 & 124 & 118 & 93 & 114 & 98 & 110 & 124 & 52 & 42 \\
\hline 167.0 & 90 & 98 & 96 & 90 & 83 & 78 & 94 & 95 & 58 & 86 \\
\hline 169.0 & 56 & 57 & 49 & 56 & 57 & 34 & 54 & 55 & 8 & 51 \\
\hline
\end{tabular}

TABLE 2. Cant deficiency and cant excess values.

\begin{tabular}{|c|c|}
\hline $\mathrm{km}$ & Average speed $\mathrm{V}[\mathrm{kph}]$ for all trains \\
\hline 161.7 & 67.84 \\
\hline 162.8 & 70.00 \\
\hline 167.0 & 75.18 \\
\hline 169.0 & 78.68 \\
\hline
\end{tabular}

TABLE 3. Average speeds of all trains.

[4] J. Valehrach, J. Smid. Monitoring of Track Sections with Long-pitch Corrugation, Proc. Int. Conf. on Interoperability of Railway Transport - IRICoN 2016. Czech Technical University in Prague, 2016. ISBN 978-80-01-05939-5.

[5] C. . 6360-1. Geometrical characteristics of railway tracks - part 1. Layout. 2008.

[6] s. o. SZDC. Superstructure plotted outline, internal

\begin{tabular}{|c|c|}
\hline $\mathrm{km}$ & All trains \\
\hline 161.7 & 57.1 \\
\hline 162.8 & 83.1 \\
\hline 167.0 & 73.7 \\
\hline 169.0 & 27.7 \\
\hline
\end{tabular}

TABLE 4. Cant deficiency values (not rounded).

information system output. Valid for 2017-04. Brno, 2017.

[7] J. Valehrach. Long-pitch Corrugation - Monitored Track Sections, Proc. Int. Conf. on Young Scientist. Technical University of Kosice, Faculty of Civil Engineering, Kosice, 2016. ISBN 978-80-553-2537-8. 